

\section{Sumário}

I. Dossiê Especial: History of International Law ...................................1

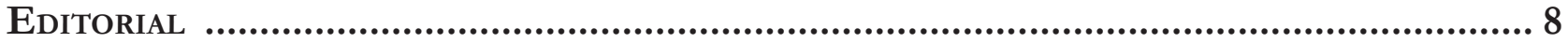

What does it mean to apply history in international law studies? ....................................................... 8

Arthur Roberto Capella Giannattasio

SuR LA NATURE DU Droit ISLAMIQUe............................................................................14

Hocine Benkheira

Islamic Shari’a Law, History and Modernity: Some Reflections .................................25 Suleiman A. Mourad

The (Un)practical Secularization Process: International Law and Religion as So-

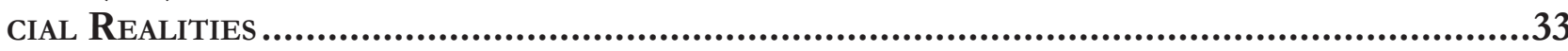

Douglas de Castro

BRAZILIAN LITERATURE ON INTERNATIONAL LAW DURING THE EMPIRE REGIME. OR THE DIFFUSION OF INTERNATIONAL LAW IN THE PERIPHERIES THROUGH APPROPRIATION AND ADAPTATION.

Airton Ribeiro da Silva Júnior

Natural, POSitivo, romano E Universal? INVESTigaÇão SObre O Direito das GENTES EM

Tomás de Aquino

Rafael Zelesco Barretto

II. Artigos sobre outros temas

VINCULAÇÃO DOS DIREITOS ECONÔMICOS, SOCIAIS E CULTURAIS: UMA DISCUSSÃO DO DESENVOLVImento humano com base no conceito de Amartya Sen sobre o mínimo existencial.....99

Natalia Mascarenhas Simões Bentes e Yasmim Salgado Santa Brígida

A NOVA LeI de MigraÇão E A PROTEÇão CONFERIDA AO APÁtrida: ALINHAMENTO BRASILEIRO AO PADRÃO INTERNACIONAL DE DIREITOS HUMANOS

Pedro Henrique de Faria Barbosa e Sylvio Loreto

E se o Supremo Tribunal Federal (STF) restabelecer a vigência da Convenção n. 158 
da Organização Internacional do Trabalho (OIT) na ordem Jurídica brasileira? SoBRE UMA POSSÍVEL REVIRAVOLTA, PELA VIA DO DIREITO INTERNACIONAL, DAS LEIS TRABALHISTAS BRASILEIRAS 138

Daniel Damasio Borges

JULGADOS DA CORTE INTERAMERICANA SOBRE CASOS BRASILEIROS E POLÍTICAS PÚBLICAS: REFLEXÕES ACERCA DE POSSÍVEIS INFLUIÇÕES 165

Rafael Osvaldo Machado Moura

CREATING BRIDGES BETWEEN INTERNATIONAL RELATIONS THEORY AND INTERNATIONAL HUMAN RIGHTS LAW: CONSTRUCTIVISM AND THE ROLE OF BRAZIL IN THE INTER-AMERICAN SYSTEM OF HUMAN RIGHTS 179

Ismael Francisco de Souza, Luciana Rocha Leme e Erick da Luz Scherf

Justiça de transição na Argentina e o Sistema Interamericano de Direitos Humanos: uMa ANÁlise do CASo Luis Muiña (“REgRa 2x1”) 199

Emilio Peluso Neder Meyer e Jessica Holl

A legalidade e legitimidade da INTERVEnÇão humanitÁria: UMA MEDIDA AINDA NECESSÁRIa.219 Natália Caye Batalha Boeira

O Acordo de Escazú E o ACESSo À INFORMaÇão AMbiental no Brasil. 252 Érica Bezerra Queiroz Ribeiro e Bruno Amaral Machado

Dos POVOS NATIVOS AO SURGIMENTO DOS MOVIMENTOS SOCIAIS: INFLUÊNCIAS DOS DISCURSOS JURÍDICOS, RELIGIOSOS E MÉDICOS PARA A CONSTRUÇÃO DO CONCEITO DE HOMOSSEXUALIDADE NO BRASIL .267 Bruno Rafael Silva Nogueira Barbosa e Robson Antão de Medeiros

Aspectos Jurídicos da PARTicipaÇão dA UNião Europeia NA OMC: COMPREENDENdo SUTILEZAS DE UM DELICADO ENLACE. 291

Camilla Capucio

Path to judicial activism? The use of "Relevant rules of international law" by the WTO Appellate Body

Mariana Clara de Andrade

LEVEZA E PESO NA MEDIAÇÃO COMERCIAL INTERNACIONAL: O CONTEÚDO JURÍDICO DO ACORDO CORPORATIVO MEDIADO E SUA INCORPORAÇÃo PELO DiREITO BRASILEIRO .324 Henrique Lenon Farias Guedes 
JURISDIÇÃO INTERNACIONAL E AS DIFICULDADES DE EXECUÇÃO DE SENTENÇAS INTERNACIONAIS NO BRASIL

Nevitton Vieira Souza

O DEVER DE COOPERAÇÃo NOS CONTRATOS DE VENDA INTERNACIONAL DE MERCADORIAS: PRESSUPOSTOS TEÓRICOS E REPERCUSSÕES PRÁTICAS DA CLÁUSULA GERAL DA BOA-FÉ OBJETIVA PARA A APLICAÇÃo DA CISG .358

Angelo Gamba Prata de Carvalho

A DiMENSÃo JURÍdiCA DO IMPERIALISMO NA (DES)ORDEM GLOBAL CAPITALISTA: UMA ANÁLISE COM BASE NA CRÍTICA MARXISTA AO DIREITO INTERNACIONAL E ÀS RELAÇÕES POLÍTICO-ECONÔMICAS DE DOMINAÇÃO E DEPENDÊNCIA.

Thomaz Delgado De David, Maria Beatriz Oliveira da Silva e Rosane Beatris Mariano da Rocha Barcellos Terra

A participaÇão de Brasil e Estados Unidos na formulação das regras multilaterais do

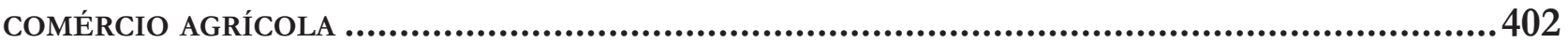

Vera Thorstensen, Vivian Daniele Rocha Gabriel e Alebe Linhares Mesquita

A galáxia lex e a construÇão de um Sistema jurídico transnacional ........................ 441

Eugênia Cristina Nilsen Ribeiro Barza e Jéssyka Maria Nunes Galvão

Has the Ability of Truth Commissions to Recommend Amnesty Been Effective in Enhancing Perpetrator Cooperation? 453 Jeremy Sarkin

A CONCEPTUAL PAPER ON THE POLICY-FRAMEWORK THAT MIRRORS THE DYNAMIC LINK BETWEEN Human Security, Social Protection and Safety Nets, and Food and Nutritional Security: The Case of the "Gulayan sa Paaralan Program", the Philippines.... 478 Renato Lagapa Base

INCENTIVISING SMALLHOLDER FARMER LIVELIHOODS AND CONSTRUCTING FOOD SECURITY THROUGH HOME-GROWN SCHOOL FEEDING: EVIDENCE FROM NORTHERN GHANA .491

Clement Mensah

Policy COHERENCE In THE IMPLEMENTATION OF THE 2030 AgENDA FOR SUSTAINABLE DEVELOpment: the Brazilian School Feeding Programme Case Study .506 Mariana Werlang Girardi 


\title{
O Acordo de Escazú e 0 acesso à informação ambiental no Brasil ${ }^{*}$
}

\section{The Escazú Agreement and the right of access to environmental information in Brazil}

\author{
Érica Bezerra Queiroz Ribeiro** \\ Bruno Amaral Machado***
}

\section{Resumo}

O objetivo deste artigo é avaliar a influência do Acordo Regional sobre Acesso à Informação, Participação Pública e Acesso à Justiça em Assuntos Ambientais na América Latina e no Caribe (Acordo de Escazú) no exercício do direito de acesso à informação ambiental no Brasil. $\mathrm{O}$ foco recai sobre dois conceitos inseridos no Acordo: a vulnerabilidade de pessoas ou grupos sociais usuários da informação ambiental e o teste de interesse público para acesso a informações de interesse particular. Ao determinar a oferta de orientação e assistência, a pessoas ou grupos em situação de vulnerabilidade, o acordo consolida precedentes do sistema interamericano de proteção dos direitos humanos, que, associados à isenção de custos de reprodução de documentos e à disponibilização de dados e informações em diferentes formatos, línguas e canais, visam garantir influência efetiva nas decisões em matéria de proteção ambiental. O teste de interesse público, como raciocínio para o balanceamento do interesse público em entregar a informação ambiental em contraposição ao interesse privado em proteger a informação de interesse particular, é discutido com base nas experiências americana, irlandesa, mexicana e brasileira. A partir da revisão ad-hoc da literatura nacional e estrangeira relacionada ao direito de acesso à informação em geral, e à informação ambiental em particular (artigos científicos, legislação e jurisprudência), entende-se que ambos os conceitos são inovações jurídicas relevantes, as quais poderão ensejar significativo incremento da transparência ambiental.

* Recebido em: 17/10/2018

Aprovado em: 07/11/2018

** Doutoranda em Direito pelo Centro Universitário de Brasília (UniCEUB). Mestre em Ciência da Informação e Bacharel em Direito pela Universidade Federal de Santa Catarina (UFSC). Auditora Federal de Finanças e Controle da Controladoria-Geral da União (CGU). E-mail : ericabqr@gmail.com

*** Doutor em Direito pela Universidade de Barcelona. Pós-doutorado em Sociologia (UnB) - John Jay (Nova Iorque). Professor da FESMPDFT e dos programas de Mestrado e Doutorado em Direito do Centro Universitário de Brasília (UniCEUB). E-mail : brunoamachado@hotmail.com
Palavras-chave: Acesso à informação ambiental. Acordo de Escazú. Vulnerabilidade. Teste de interesse público.

\section{Abstract}

The objective of this article is to evaluate the influence of the Regional Agreement on Access to Information, Public Participation and Justice in Environmental Matters in Latin America and the Caribbean (Escazú Agreement) in the exercise of the right of access to environmental information in Brazil. The focus of the analysis falls on two concepts included in the Agreement: the vulnerability of individuals or social groups that use environmental information and the public interest test for access to informa- 
tion of private interest. In determining the provision of guidance and assistance to persons or groups in vulnerable situations, the Agreement consolidates precedents of the inter-American system for the protection of human rights, which, together with the exemption of reproduction costs of documents and the availability of data and information in different formats, languages and channels, aim to ensure effective influence on decisions on environmental protection. Public interest testing, as a reasoning for balancing the public interest in delivering environmental information as opposed to private interest in protecting information of particular interest, is discussed from the American, Irish, Mexican and Brazilian experiences. Based on the ad-hoc review of the national and foreign literature related to the right of access to information in general, and to the environmental information in particular (scientific articles, legislation and jurisprudence), both concepts are considered relevant legal innovations, which may lead to a significant increase in environmental transparency.

Keywords: Access to environmental information. Escazú Agreement. Vulnerability. Public interest test.

\section{INTRODUÇão}

É recorrente na literatura especializada atribuir à Constituição Cidadã a origem do direito de acesso à informação em nosso país. Argumenta-se nesse sentido considerando que o inciso XXXIII do artigo $5^{\circ}$ da Constituição registra o direito de receber informações de interesse particular, coletivo ou geral ${ }^{1}$.

Contudo, o Poder Legislativo já havia disposto sobre esse direito fundamental, de modo explícito, na Lei

1 BANISAR, David. Freedom of information around the world 2006: a global survey of access to government information laws. Londres: Privacy International, 2006. CUNHA FILHO, Marcio Camargo; XAVIER, Vitor Cesar Silva. Lei de acesso à informação: teoria e prática. Rio de Janeiro: Lumen Juris, 2014. MENDEL, Toby. Liberdade de informação: um estudo de direito comparado. 2. ed. Brasília: UNESCO, 2009. MICHENER, Gregory. Assessing freedom of information in Latin America a decade later: illuminating a transparency causal mechanism. Journal of Latin American Politics and Society, Miami, v. 57, n. 3, p. 11-99, 2015. Organização para a Cooperação e Desenvolvimento Econômico (OCDE). Access to Public Information in Latin America. In: OPEN Government in Latin America. Paris: OCDE, 2014. Disponível em: http://www.keepeek.com/Digital-AssetManagement/oecd/governance/open-government-in-latin-america/access-to-public-information-in-latin-america_97892642236396-en\#page28. Acesso em: 11 nov. 2018.
6.938/1981, ao estabelecer como objetivos da Política Nacional do Meio Ambiente a "divulgação de dados e informações ambientais" e a "formação de uma consciência pública sobre a necessidade de preservação da qualidade ambiental e do equilíbrio ecológico" (inciso $\mathrm{V}$ do artigo $4^{\circ}$ ). Coerente com o caráter inovador dessa Lei em seu aspecto geral, esse objetivo foi dotado de instrumento também à frente de seu tempo, o sistema nacional de informações sobre o meio ambiente (Sini$\mathrm{ma}$ - inciso VII do artigo $9^{\circ}$ ), ao qual se somou, por meio da Lei 7.804/1989, a obrigação de o Poder Público produzir informações inexistentes (inciso VIII do artigo $9^{\circ}$ ). Esses dispositivos foram detalhados pela Lei 10.650/2003, a qual tratou do acesso público a dados e informações existentes nos órgãos e entidades integrantes do Sistema Nacional do Meio Ambiente (Sisnama), estabelecendo prazos e procedimentos para o exercício desse direito.

Desse modo, as bases do que hoje se entende por transparência ambiental (pro) ativa e passiva foram estabelecidas muito antes do advento da Lei 12.527/2011, conhecida por Lei de Acesso à Informação (LAI). Essa lei determinou prazos e condições para o exercício do direito de acesso à informação, bem como estabeleceu competências para promoção da transparência do Estado, com abrangência nacional, impulsionando o acesso à informação ambiental. É possível afirmar, grosso modo, que o quadro jurídico brasileiro, em matéria de acesso à informação ambiental, é atualmente constituído pelas três leis ${ }^{2}$.

Alteração significativa nesse quadro, todavia, deve advir da ratificação do Acordo Regional sobre Acesso

2 Nesse sentido: BARROS, Lucivaldo Vasconcelos. O Estado (in) transparente: limites do direito à informação socioambiental no Brasil. 2008. Tese (Doutorado em Desenvolvimento Sustentável) - Universidade de Brasília, Brasília, 2008. COSTA, Beatriz Souza; SAMPAIO, José Adércio Leite. Acesso à informação digital no Brasil em casos de acidentes: o exemplo da tragédia de Mariana. Revista Veredas do Direito, Belo Horizonte, v. 14, n. 30, p. 77-98, 2017. LANCHOTTI, Andressa de Oliveira; DIZ, Jamile Bergamaschine Mata. Direito de acesso à informação ambiental: da formalidade à efetividade dos direitos de acesso. Revista de Direito e Sustentabilidade. Curitiba, v. 2, n. 2, p. 130-148, 2016. MONEBHURRUN, Nitisch. Estudo comparativo do Direito de acesso à informação ambiental na Argentina, no Brasil e na Bolívia: medindo os tons da transparência ambiental. In: GAUTREAU, Pierre; MONEBHURRUN, Nitisch (org.). Direito à informação ambiental: uma agenda de pesquisa interdisciplinar. $\mathrm{Cu}-$ ritiba: Prismas, 2017. PAES, Luciano Marcos. Participação popular e acesso à informação ambiental para preservação do meio ambiente ecologicamente equilibrado. Revista Brasileira de Políticas Públicas, Brasília, v.5, n. 2, p. 277-287, 2015. 
à Informação, Participação Pública e Acesso à Justiça em Assuntos Ambientais na América Latina e no Caribe, aprovado em Escazú (Costa Rica) em 4 de março de 2018 e assinado em 27 de setembro. Explicitamente inspirado na Convenção de Aarhus, o Acordo de Escazú contém disposições específicas para acesso à informação ambiental por pessoas e grupos em situação de vulnerabilidade, implicando assistência especial desde o recebimento do pedido. Ao também estabelecer critérios gerais para aplicação de teste do interesse público, o Acordo aumenta o ônus do Estado para justificar uma negativa de acesso à informação ambiental, em favor da máxima divulgação de informações. Essas duas disposições podem operar uma verdadeira transformação da lógica de acesso à informação em geral, na medida em que se comportam como instrumentos de argumentação de alto impacto, os quais podem ser extrapolados para justificar o acesso a outras informações para além da matéria ambiental, inclusive.

O presente artigo tem, como principal objetivo, discutir essas importantes inovações do Acordo de Escazú à luz do quadro jurídico brasileiro para o acesso à informação ambiental. A pergunta central da presente pesquisa é: o quadro jurídico brasileiro, com base na ratificação e na entrada em vigência do Acordo de Escazú, cria condições para o incremento da transparência e do acesso à informação ambiental em nosso país? O estudo parte da hipótese de que o ordenamento jurídico brasileiro é suficientemente robusto para garantir a transparência ativa e passiva da informação ambiental. Todavia, as disposições legais, no Brasil, não estabeleceriam, adequadamente, as hipóteses para excepcionar a aplicação das restrições ao acesso à informação ambiental em prol da proteção do meio ambiente, limitação esta que dificultaria a participação social. Existiriam, ademais, dispositivos que confeririam ao Estado demasiada amplitude interpretativa, a qual não guardaria equilíbrio com a aplicação do princípio da máxima divulgação, fundamental para a garantia do direito de acesso a informações. Para além das restrições ao acesso à informação ambiental, o quadro jurídico atual não garantiria o acesso por pessoas e grupos sociais vulneráveis, razão pela qual a vigência do Acordo de Escazú resultaria no incremento da proteção ambiental.

Organizado em três itens, no primeiro registra os principais argumentos em favor da transparência e do acesso à informação para a proteção ambiental, com base no qual constrói, no item seguinte, o quadro jurídi- co de referência para o acesso ambiental no Brasil. No terceiro e último item, discutem-se os dispositivos do Acordo que tratam do acesso à informação ambiental por pessoas e grupos em situação de vulnerabilidade e do teste do interesse público, sob a perspectiva da promoção da participação social, avaliando-se suas potencialidades e limitações.

\section{TRANSPARÊNCIA, ACESSO À INFORMAÇÃO E PROTEÇÃO AMBIENTAL}

No âmbito do direito internacional, os primeiros esforços para alinhamento da transparência com a proteção ambiental remontam à Agenda 21, a qual estabeleceu, como princípio para cooperação internacional para o desenvolvimento sustentável, a participação pública na formulação, negociação e implementação de políticas comerciais enquanto meio de originar maior transparência. A operacionalidade desse princípio foi conferida, também, pela Conferência das Nações Unidas sobre o Meio Ambiente e o Desenvolvimento (Cnumad), a qual registrou, por meio do Princípio 10 da Declaração do Rio sobre o Meio Ambiente e o Desenvolvimento, a correlação entre a transparência ambiental e o direito de acesso a informações.

O recurso à transparência como instrumento de política ambiental decorre do reconhecimento da suposta insuficiência dos mecanismos jurídicos e econômicos clássicos para inibição e punição de condutas poluidoras do meio ambiente, ao induzir processos de autorreflexão e de autocrítica para avaliação da performance ambiental das entidades reguladas ${ }^{3}$. A transparência viabilizaria, dessa forma, que a sociedade civil exercesse pressão sobre empresas, governos e autoridades judiciárias, impactando a forma como a empresa é percebida por seus consumidores, fomentando o controle social em paralelo à regulação oficial e atualizando o poder judiciário sobre os valores e parâmetros de referência para decisões socialmente justas. Esse entendimento, contudo, é também rechaçado por desconsiderar as disparidades de acesso e uso da informação por grandes

3 ALOGNA, Ivano; ALBUQUERQUE, Marcia Fajardo Cavalcanti de. Os modelos de divulgação de informação ambiental: experiências comparadas e perspectivas para o Brasil. In: GAUTREAU, Pierre; MONEBHURRUN, Nitisch (org.). Direito à informação ambiental: uma agenda de pesquisa interdisciplinar. Curitiba: Prismas, 2017. p. $313-340$ 
corporações, solicitantes individuais ou comunitários, as quais resultariam em maior opacidade nas áreas de supervisão e regulação do mercado ${ }^{4}$.

A transparência ambiental também poderia promover o incremento do sistema regulatório sob outras frentes. Diante da insuficiência de dados e informações ambientais detidos ou produzidos pelos órgãos públicos, a integração e o compartilhamento de bases de dados subnacionais, nacionais e internacionais, mediante padrões tecnológicos comuns ou interoperáveis, é a tendência ${ }^{5}$.

A capacidade de aprendizagem institucional, a qual facilita a adaptação frente à mudança ambiental, social, econômica ou política, bem como o registro e a transmissão de conhecimentos e experiências, pode ser medida com base na capacidade de avaliação e da complexidade do sistema de informação ambiental ${ }^{6}$. Em um estado ótimo, quando a própria sociedade produz dados para comparação com os dados oficiais, o reuso desses dados pelos gestores e técnicos ambientais promove verdadeira co-construção da política ambiental, aumentando o compliance às normas e a adaptação à mudança ${ }^{7}$.

Ademais, o direito de acesso à informação criaria condições para incremento da participação social na estruturação do direito ambiental global ${ }^{8}$. No Brasil, as iniciativas para transparência de dados e informações ambientais foram registradas em diferentes leis, cuja

4 POZEN, David E. Transparency's Ideological Drift. Yale Law Journal, set. 2018. Disponível em: https://papers.ssrn.com/sol3/papers.cfm?abstract_id=3120807. Acesso em: 11 nov. 2018.

5 GAUTREAU, Pierre. Entre democracia informacional y posneoliberalismo: una ecología política de los dispositivos de open data ambiental. In: GAUTREAU, Pierre; MONEBHURRUN, Nitisch (org.). Direito à informação ambiental: uma agenda de pesquisa interdisciplinar. Curitiba: Prismas, 2017. p. 183-206.

6 SANTANA, Ana Cláudia Farranha; SUGUIURA, Carolina. Acesso à informação ambiental e considerações metodológicas sobre avaliação: é possível identificar como funcionam os sistemas de informação? In: GAUTREAU, Pierre; MONEBHURRUN, Nitisch (org.). Direito à informação ambiental: uma agenda de pesquisa interdisciplinar. Curitiba: Prismas, 2017. p. 159-182.

7 SANDRA, Nicolle; MAYA, Leroy. Compartir y difundir datos públicos medioambientales: estrategias en la amazonia francesa y brasileña. In: GAUTREAU, Pierre; MONEBHURRUN, Nitisch (org.). Direito à informação ambiental: uma agenda de pesquisa interdisciplinar. Curitiba: Prismas, 2017. p. 229-260.

8 BALBINO, Michelle Lucas Cardoso. A participação social na construção do direito ambiental global. Revista de Direito Internacional, Brasília, v. 14, n. 3, p. 79-104, 2017. LEUZINGER, Marcia Dieguez; SILVA, Solange Teles da. O princípio da participação e a criação e gestão das áreas protegidas na perspectiva do direito ambiental global. Revista de Direito Internacional, Brasília, v. 14, n. 3, p. 134-146, 2017. análise será objeto do próximo item.

\section{A RELEVÂNCIA do QUAdRo nORMATIVO BRASILEIRO PARA PROMOÇÃO DA TRANSPARÊNCIA AMBIENTAL}

O exercício do direito fundamental de acesso a informações funda-se no pressuposto de que a publicidade é a regra e, o sigilo, a exceção. Esse enunciado, denominado Princípio da Máxima Divulgação, é explícito em todos os mais importantes pactos e declarações que registram esse direito, os quais apontam, em linhas gerais, hipóteses para sua restrição.

É frequente remontar ao artigo 19 da Declaração Universal dos Direitos do Homem (1948) para se fixar a origem desse direito ${ }^{9}$, por meio do qual se garantiu a faculdade de "[...] procurar, receber e difundir, sem consideração de fronteiras, informações e ideias por qualquer meio de expressão". O Pacto Internacional sobre Direitos Civis e Políticos (1966) tornou explícitos, também no artigo 19, os componentes fundamentais desse direito humano, estabelecendo critérios para sua eventual restrição, dentre os quais a necessidade de “: a) assegurar o respeito dos direitos e da reputação das demais pessoas; e b) proteger a segurança nacional, a ordem, a saúde ou a moral públicas". Nos mesmos termos, o Pacto de São José da Costa Rica (1969) reforçou os elementos trazidos pelo Pacto anterior. Em outubro de 2000, a Comissão Interamericana de Direitos Humanos adotou a Declaração de Princípios sobre Liberdade de Expressão, reforçando seu caráter fundamental e a

9 COMISSÃO INTERAMERICANA DE DIREITOS HUMANOS (CIDH). O direito de acesso à informação no Marco Jurídico Interamericano. 2011. Disponível em: https://www.oas.org/pt/cidh/ expressao/docs/publicaciones/20140519\%20-\%20port\%20unesco $\% 20-\% 20$ el $\% 20$ derecho $\% 20$ de $\% 20$ acceso $\% 20 \mathrm{a} \% 201 \mathrm{a} \% 20$ informacion $\% 202 \mathrm{a} \% 20$ edicion $\% 20$ adjusted.pdf. Acesso em: 11 nov. 2018. MENDEL, Toby. Liberdade de informação: um estudo de direito comparado. 2. ed. Brasília: UNESCO, 2009. MICHENER, Gregory. Assessing freedom of information in Latin America a decade later: illuminating a transparency causal mechanism. Journal of Latin American Politics and Society, Miami, v. 57, n. 3, p. 11-99, 2015. Organização para a Cooperação e Desenvolvimento Econômico (OCDE). Access to Public Information in Latin America. In: OPEN Government in Latin America. Paris: OCDE, 2014. Disponível em: http:// www.keepeek.com/Digital-Asset-Management/oecd/governance/ open-government-in-latin-america/access-to-public-informationin-latin-america_9789264223639-6-en\#page28. Acesso em: 11 nov. 2018. 
necessidade de previsão em lei das hipóteses de restrição de acesso, sob os mesmos critérios.

A esse movimento em prol do acesso a informações se somou outro, relativo à crescente adoção pelo Brasil de parâmetros internacionais para a proteção do meio ambiente. Inicialmente tímida e de caráter desenvolvimentista, a participação do país nas conferências internacionais, gradativamente, passou a se pautar pela proteção ambiental, considerando sua extensão geográfica, com diversos tipos de biomas e grande quantidade de água doce e espécies da flora e da fauna ${ }^{10}$.

Desse contexto resultou a Lei 6.938/1981, de iniciativa do Poder Executivo federal, a qual estabeleceu a Política Nacional do Meio Ambiente, constituiu o Sisnama, criou o Conselho Nacional do Meio Ambiente (Conama) e instituiu o Cadastro Técnico Federal de Atividades e Instrumentos de Defesa Ambiental (CTF). Dentre os objetivos da Política Nacional do Meio Ambiente, estão a divulgação de dados e informações ambientais e o estímulo à formação de uma consciência pública sobre a necessidade de preservação da qualidade ambiental e do equilíbrio ecológico (inciso $\mathrm{V}$ do artigo $4^{\circ}$ ), instrumentalizados pelo Sinima. Alterada pela Lei 7.804/1989, a Lei 6.938/1981 passou a incluir a “[...] garantia da prestação de informações relativas ao Meio Ambiente, obrigando-se o Poder Público a produzi-las, quando inexistentes" (inciso VIII do artigo $9^{\circ}$ ).

Referida Lei forneceu os fundamentos para garantia do acesso à informação ambiental, na medida em que conferiu ao Estado a obrigação de produzir e disseminar informações — associando-a à premência do fomento da cultura de proteção ambiental e da participação social - e determinou a sistematização das informações sobre meio ambiente. Produção, gestão e disseminação da informação, enquanto engrenagens de uma espécie de "ciclo da informação", estimulariam crescentes níveis de transparência e participação social que, por sua vez, alavancaria o desenvolvimento sustentável. No entanto, diante da inexistência de disposições para operacionalização do direito de acesso à informação ambiental, tais objetivos, instrumentos e garantias

10 DIZ, Jamile Bergamaschine Mata; DISCACCIATI, Ana Clara Gonçalves. Acesso à informação ambiental: por um novo paradigma de participação. Revista Direito e Liberdade, Natal, v. 17, n. 3, p. 71-113, 2015.

11 CHOO, Chun Wei. A organização do conhecimento: como as organizações usam a informação para criar significado, construir conhecimento e tomar decisões. São Paulo: SENAC, 2003. não produziram esses efeitos, inicialmente.

A partir da Conferência das Nações Unidas sobre o Meio Ambiente e o Desenvolvimento (Cnumad), realizada no Rio de Janeiro de 3 a 14 de junho de 1992, o direito de acesso à informação ambiental ganhou impulso para, enfim, se tornar procedimentalmente viável. O Princípio 10 da Declaração do Rio sobre o Meio Ambiente e o Desenvolvimento não só reforçou a importância da garantia do direito de acesso como registrou a evidente correlação entre informação e participação social para a proteção do meio ambiente:

Princípio 10: O melhor modo de tratar as questões ambientais é com a participação de todos os cidadãos interessados, no nível que corresponda. No plano nacional, toda a pessoa deverá ter acesso adequado à informação sobre o meio ambiente de que disponham as autoridades públicas, incluída a informação sobre os materiais e as atividades que encerram perigo em suas comunidades, bem como a oportunidade de participar nos processos de adoção de decisões.

Essa correlação, todavia, não foi explicitamente espelhada na Lei $10.650 / 2003$, a qual dispôs sobre o acesso público aos dados e informações existentes nos órgãos e entidades integrantes do Sisnama. No entanto, essa lacuna não macula sua relevância enquanto marco para o acesso à informação ambiental no Brasil, considerando suas disposições relativas à sujeição passiva e ativa à Lei, ao seu objeto, aos prazos e procedimentos para acesso e recurso administrativo em caso de negativa, bem como à forma e ao rol mínimo de informações que deveriam ser objeto de divulgação proativa ${ }^{12}$.

Constituído pelos órgãos e entidades da União, dos Estados, do Distrito Federal, dos Territórios e dos $\mathrm{Mu}-$ nicípios, bem como pelas fundações públicas, responsáveis pela proteção e melhoria da qualidade ambiental, o Sisnama delimitou os sujeitos passivos das obrigações de transparência ativa e passiva impostas pela Lei 10.650/2003 $\left(\operatorname{artigo~} 1^{\circ}\right.$ ). Desse modo, informações para proteção do meio ambiente, detidas por um banco público de fomento ao desenvolvimento, não poderiam ser objeto de solicitação com fundamento na referida Lei.

Qualquer indivíduo, nacional ou estrangeiro, podia solicitar o acesso à informação ambiental sob a guarda dos órgãos e entidades do Sisnama (artigo $2^{\circ}$ ). Não era

12 MACHADO, Paulo Affonso Leme. Direito à informação e meio ambiente. 2. ed. São Paulo: Malheiros, 2018. 
necessário declinar "interesse específico" para acesso à informação ambiental; no entanto, o solicitante não poderia utilizá-la para fins comerciais e tinha a obrigação de citar a fonte caso viesse a divulgá-la (parágrafo $1^{\circ}$ do $\operatorname{artigo} 2^{\circ}$ ).

Os pedidos podiam veicular o acesso a quaisquer documentos, expedientes e processos administrativos em matéria ambiental, em especial àqueles relacionados à qualidade do meio ambiente; a políticas, planos e programas potencialmente causadores de impacto ambiental; aos resultados de monitoramento e auditoria nos sistemas de controle de poluição e de atividades potencialmente poluidoras, bem como de planos e ações de recuperação de áreas degradadas; a acidentes, situações de risco ou de emergência ambientais; às emissões de efluentes líquidos e gasosos, e produção de resíduos sólidos; a substâncias tóxicas e perigosas; à diversidade biológica; e aos organismos geneticamente modificados (caput do artigo $2^{\circ}$ ). Os órgãos e entidades poderiam negar acesso à informação ambiental se protegida por sigilo comercial, industrial, financeiro ou qualquer outro sigilo protegido por lei, e das comunicações internas dos órgãos e entidades governamentais, cabendo a quem fornecer a informação advertir o órgão ou entidade acerca dessas circunstâncias legais (parágrafos $2^{\circ}$ e $3^{\circ}$ do artigo $2^{\circ}$ ). Nenhum parâmetro para flexibilização desses sigilos foi estabelecido pela Lei, sequer a existência de um interesse público prevalente. A negativa devido ao sigilo de comunicações estabelecia uma hipótese de restrição de acesso vaga, inclusive.

O pedido deveria ser apresentado por escrito e atendido em até 30 dias corridos. A negativa do acesso à informação ambiental deveria ser motivada, estando sujeita a recurso hierárquico (parágrafo $5^{\circ}$ do artigo $2^{\circ} \mathrm{e}$ caput do artigo $5^{\circ}$ ).

Significativo mérito da Lei 10.650/2003 se refere às disposições sobre transparência ativa de informação ambiental, exigindo-se publicação, no Diário Oficial, de determinados atos administrativos, como pedido, renovação e concessão de licenciamento, penalidades impostas e termos de compromisso de ajustamento de conduta (artigo $4^{\circ}$ ). Essas informações deveriam ser organizadas em listagens de fácil acesso ao público (parágrafo único do artigo $4^{\circ}$ ). Todos os órgãos do Sisnama deveriam produzir e divulgar, anualmente, relatórios relativos à qualidade do ar e da água (artigo $8^{\circ}$ ).

A partir da entrada em vigor da Lei 10.650/2003, o Ministério do Meio Ambiente constituiu, por meio da Portaria MMA 310/2004, o comitê gestor do Sinima, responsável por "[...] homologar e promover nacionalmente os padrões de interoperabilidade entre os sistemas de informação do Ministério do Meio Ambiente e dos órgãos vinculados, componentes do Sistema Nacional do Meio Ambiente-SISNAMA e outros, objetivando o compartilhamento dos dados relevantes dos sistemas em questão"; e por "propor estratégias de disseminação da informação ambiental" (incisos VI e IX do artigo $2^{\circ}$ ). O sistema foi oficialmente lançado em 8 de junho de 2006, tornando possível o acesso integrado a dados do Portal Nacional de Licenciamento Ambiental (PNLA), do Sistema de Bases Compartilhadas de Dados sobre a Amazônia (BCDAM), da Rede Virtual de Informação da Caatinga (RVC), do Sistema de Informação do Gerenciamento Costeiro e Marinho (Sigercom), do Sistema de Informação do Rio São Francisco (Sisfran), do Sistema Brasileiro de Informação sobre Educação Ambiental (Sibea) e do Sistema de Informação Ambiental do Mercosul (Siam)"13. No mesmo ano, a transparência ativa da informação ambiental florestal foi objeto do Decreto 5.975/2006, o qual determinou sua disponibilidade na internet e no Sinima.

As disposições da Lei 10.650/2003 e da regulamentação dela decorrente estavam alinhadas com as mais modernas provisões em matéria de direito de acesso a informações, especialmente no que se referia à desnecessidade de declinar motivos para o acesso a documentos e processos administrativos de interesse público e de se conferir máxima publicidade para promoção do controle e da participação social. Os procedimentos que estabeleceu para transparência passiva da informação ambiental, no entanto, careciam de disposições para efetivas, considerando-se o caráter genérico das disposições relacionadas às hipóteses para negativa de acesso e à possibilidade de interpor recurso em face da negativa. Essas lacunas foram superadas com a regulamentação do inciso XXXIII do artigo $5^{\circ}$ da Constituição Federal.

O direito de acesso a informações foi, apenas recentemente, objeto de Lei em nosso país. O Brasil foi o $91^{\circ}$ país a regulamentá-lo, após Chile, México, Peru e Uruguai $^{14}$. Por meio da Lei 12.527 , de 18 de novembro

13 SILVA, Thiago Antunes da. Avaliação do acesso ao SINIMA Sistema Nacional de Informação sobre o meio ambiente. Perspectivas em Ciência da Informação, Belo Horizonte, v. 12, n. 3, p. 41-53, 2007.

14 VLEUGELS, Roger. Overview of all FOI laws. Disponível em: http://www.right2info.org/resources/publications/laws-1/ati-laws_ fringe-special_roger-vleugels_2011-oct. Acesso em: 11 nov. 2018. 
de 2011, o Brasil estabeleceu os procedimentos relacionados ao direito fundamental de acessar, consultar e obter informações produzidas, acumuladas ou custodiadas pelo Estado, de interesse público ou particular, exercido mediante solicitação (transparência passiva) ou consulta a repositórios físicos ou online (transparência ativa). Nos níveis estadual e municipal, e nos Poderes Legislativo e Judiciário, foi objeto de regulamentações específicas, a despeito da abrangência nacional conferida originariamente à $\mathrm{LAI}^{15}$.

A Lei estabeleceu um conjunto de hipóteses para restrição do acesso a informações, as quais podem ser organizadas do seguinte modo:

a) Informações classificadas: são aquelas consideradas imprescindíveis à segurança da sociedade ou do Estado, cuja divulgação ou acesso irrestrito possa, nos termos do artigo 23 da LAI, vulnerar determinados interesses:

Art. 23. São consideradas imprescindíveis à segurança da sociedade ou do Estado e, portanto, passíveis de classificação as informações cuja divulgação ou acesso irrestrito possam:

I - pôr em risco a defesa e a soberania nacionais ou a integridade do território nacional;

II - prejudicar ou pôr em risco a condução de negociações ou as relações internacionais do País, ou as que tenham sido fornecidas em caráter sigiloso por outros Estados e organismos internacionais;

III - pôr em risco a vida, a segurança ou a saúde da população;

IV - oferecer elevado risco à estabilidade financeira, econômica ou monetária do País;

$\mathrm{V}$ - prejudicar ou causar risco a planos ou operações estratégicos das Forças Armadas;

VI - prejudicar ou causar risco a projetos de pesquisa e desenvolvimento científico ou tecnológico, assim como a sistemas, bens, instalações ou áreas de interesse estratégico nacional;

VII - pôr em risco a segurança de instituições ou de altas autoridades nacionais ou estrangeiras e seus familiares; ou

VIII - comprometer atividades de inteligência, bem como de investigação ou fiscalização em andamento, relacionadas com a prevenção ou repressão de infrações.

Nessas situações, é possível restringir, por até 50

15 O Ministério da Transparência e Controladoria-Geral da União reuniu, em um único site, a legislação estadual e municipal referente ao direito de acesso a informações: http://www.cgu.gov.br/assuntos/transparencia-publica/brasil-transparente/legislacao. anos, o acesso a determinados dados e informações, mediante procedimento solene, materializado em um documento denominado Termo de Classificação de Informações (TCI). É possível solicitar a desclassificação ou a reclassificação dos dados e informações, observando-se procedimentos específicos.

b) Sigilos legais: informações protegidas por sigilo bancário, fiscal, profissional, empresarial ou industrial, por exemplo, bem como pelo segredo de justiça, não poderão ser fornecidas, regra geral, considerando-se o disposto no artigo 22 da LAI.

c) Informações pessoais: sujeitam-se a restrição de acesso, pelo prazo máximo de 100 anos, as informações relativas à intimidade, vida privada, honra e imagem das pessoas naturais. É comum afirmar que o direito à privacidade estaria associado a uma espécie de direito de controle sobre as informações de cada um e de determinar como a esfera privada deve ser constituída ${ }^{16}$. Com a entrada em vigor da Lei 13.709/2018 (Lei Geral de Proteção de Dados Pessoais), em 14 de fevereiro de 2020, um conjunto de restrições e condições se somará àquelas inseridas na LAI, cujo cumprimento, em nível federal, será monitorado por uma nova autarquia, criada por meio da Medida Provisória 869, de 27 de dezembro de $2018^{17}$.

d) Sigilos circunstanciais: em determinadas circunstâncias, é possível restringir o acesso a informações. É o caso das informações referentes a atos administrativos ainda não concluídos, quando o acesso prévio puder representar prejuízo considerável para a decisão a ser adotada, conforme disposto no parágrafo $3^{\circ}$ do artigo $7^{\circ}$ da LAI. Obviamente, o acesso é garantido após a edição do ato.

Quaisquer dessas hipóteses de restrição de acesso, todavia, pode ser afastada para tutela judicial ou administrativa de direitos fundamentais, nos termos do artigo $21 \mathrm{da}$ Lei, bem como para conhecimento de condutas que impliquem violação dos direitos humanos praticada por agentes públicos ou a mando de autoridades públicas, conforme disposto no parágrafo único do mesmo dispositivo legal.

Por ser lei de âmbito nacional, a LAI se aplica a todos

16 SCHREIBER, Anderson. Direitos da personalidade. São Paulo: Atlas, 2014. SOLOVE, Daniel J. Understanding Privacy. Cambridge: Harvard University Press, 2008.

17 DONEDA, Danilo. Da privacidade à proteção de dados pessoais. Rio de Janeiro: Renovar, 2006. 
os poderes e esferas de governo. O Decreto 7.724/2012 regulamentou a LAI e se aplica a todos os órgãos e entidades do Poder Executivo federal. Nele, encontram-se restrições adicionais ao Princípio da Máxima Divulgação, como aquela que veda a divulgação de informações produzidas ou acumuladas por estatais que possam vulnerar "[...] sua competitividade, governança corporativa e, quando houver, os interesses de acionistas minoritários" (parágrafo $1^{\circ}$ do artigo $5^{\circ}$ ), bem como o acesso a informações "[...] obtidas pelo Banco Central do Brasil [...] no exercício de atividade de controle, regulação e supervisão da atividade econômica cuja divulgação possa representar vantagem competitiva a outros agentes econômicos" (parágrafo $2^{\circ}$ do artigo $5^{\circ}$ ). O Decreto, também, sugere que limitações de recursos humanos ou tecnológicas possam justificar a restrição ao acesso a informações, conforme disposto no artigo 13:

Art. 13. Não serão atendidos pedidos de acesso à informação:

I - genéricos;

II - desproporcionais ou desarrazoados; ou

III - que exijam trabalhos adicionais de análise, interpretação ou consolidação de dados e informações, ou serviço de produção ou tratamento de dados que não seja de competência do órgão ou entidade.

Parágrafo único. $\mathrm{Na}$ hipótese do inciso III do caput, o órgão ou entidade deverá, caso tenha conhecimento, indicar o local onde se encontram as informações a partir das quais o requerente poderá realizar a interpretação, consolidação ou tratamento de dados.

Uma vez negado o acesso à informação solicitada, o demandante poderá apresentar recurso à autoridade hierarquicamente superior à que exarou a decis a busca pelo termo "sinima" no buscador Google traz, como primeiro resultado, a página http://www.mma.gov. br/informacoes-ambientais.html, na qual foram reunidas informações sobre o Plano de Dados Abertos (PDA) do MMA, criado a partir da LAI e do Decreto 8.777/2016, que instituiu a Política de Dados Abertos do Poder Executivo federal. O Ministério disponibiliza, na página http://www.dados.mma.gov.br, 10 conjuntos de dados mantidos pelo MMA e pelo Serviço Florestal Brasileiro (SFB). Já na página http:/ /www.dados.gov.br, pesquisando-se pelo termo "meio ambiente", 58 conjuntos de dados foram recuperados. Se, de fato, os dados e informações se encontram disponíveis para reuso, não necessariamente o acesso se tornou simples e útil para aqueles que não estão familiarizados com softwares de tratamento de dados. O maior acesso às tecnologias de informação e comunicação (TICs) representa avanço fundamental para a proteção ambiental com participação social; todavia, restringem a participação àqueles que possuem competências especializadas, resultando, frequentemente, em maior exclusão.

Desse modo, o quadro jurídico brasileiro, em matéria de acesso à informação ambiental, é atualmente constituído pelas Leis 6.938/1981, 10.650/2003 e 12.527/2011. O Acordo de Escazú deverá operar nova transformação nesse quadro, a partir de inovações procedimentais e finalísticas nele introduzidas, ponto que será explanado no próximo item.

\section{A CONDIÇÃO DE VULNERABILIDADE DO SOLICITANTE E O TESTE DO INTERESSE PÚBLICO COMO INOVAÇÕES ADVINDAS DO ACORDO DE ESCAZÚ PARA INCREMENTO DA TRANSPARÊNCIA AMBIENTAL}

O Acordo de Escazú representa o mais recente e amplo esforço regional para conferir efetividade ao Princípio 10 da Declaração do Rio sobre o Meio Ambiente e o Desenvolvimento. Explicitamente inspirado na Convenção sobre o Acesso à Informação, Participação do Público no Processo de Tomada de Decisão e Acesso à Justiça em Matéria de Ambiente (Convenção de Aarhus), contém disposições que poderão elevar o direito ao acesso à informação ambiental a outro patamar, especialmente no que toca ao acesso por pessoas e grupos sociais vulneráveis.

O Acordo é resultado de 2 anos de reuniões do Comitê de Negociação, conduzidas por Chile, Costa Rica, Argentina, México, Peru, São Vicente e Granadinas e Trinidad e Tobago com delegados governamentais, representantes do público e do setor acadêmico, especialistas e outras partes interessadas. Quinze países já assinaram o Acordo, aguardando-se a ratificação de, ao menos, 11 países para que entre em vigência.

O objetivo do Acordo é:

[...] garantir a implementação plena e efetiva, na América Latina e no Caribe, dos direitos de acesso a informação ambiental, participação pública nos processos de tomada de decisões ambientais e acesso à justiça em questões ambientais, bem 
como a criação e o fortalecimento das capacidades e cooperação, contribuindo para a proteção do direito de cada pessoa, das gerações presentes e futuras, a viver em um meio ambiente saudável e a um desenvolvimento sustentável (artigo 1).

A relação de interdependência entre os três direitos de acesso é o ponto de partida do Acordo de Escazú, trazendo à vista a necessidade de se criarem condições para o exercício desses direitos por todos, independentemente de sua condição econômica, tecnológica, social ou política. O texto deixa explícita a obrigação de incluir, dentre o público objeto desses direitos, as pessoas ou grupos em situação de vulnerabilidade, entendidos como aqueles "[...] que encontram especiais dificuldades para exercer com plenitude os direitos de acesso [...], pelas circunstâncias ou condições entendidas no contexto nacional de cada Parte e em conformidade com suas obrigações internacionais" (artigo 2).

Inicialmente, cumpre destacar que o tema sofre a influência da Declaração da ONU sobre os Direitos das Pessoas Pertencentes a Minorias Nacionais, Étnicas, Religiosas ou Linguísticas (1992), a qual lhes garantiu o direito de participar nas decisões, nos níveis nacional e regional, relacionadas à minoria a que pertencem ou às regiões em que vivem (artigo 2$)^{18}$. Essas minorias, situando-se à margem do processo de consolidação dos Estados nacionais, encontram nas cortes regionais e internacionais a oportunidade de garantirem direitos nacionalmente negados, especialmente ao da participação social. Considerando um status quo nacional que mantém cenários discriminatórios entendidos como naturais, "os órgãos internacionais podem auxiliá-las no rompimento dessa realidade, confrontando-a com os tratados ratificados pelos Estados que consagram determinados bens jurídicos"19. Essa solução, no entanto, carece da própria definição de minoria nacional, de modo que o Acordo de Escazú não só reforça suas disposições como inova no tratamento conferido às pessoas e aos grupos em situação de vulnerabilidade, aqui entendidos não como sinônimo de minoria, mas, como parcialmente cumuláveis.

18 NAÇÕES UNIDAS. Declaración so $\neg$ bre los derechos de las personas pertenecientes a minorías nacionales o étnicas, religiosas y lingüísticas. 1992. Disponível em: http://www.ohchr.org/ Documents/Issues/Minorities/Booklet_Minorities_Spanish.pdf. Acesso em: 11 nov. 2018 19 LOPES, Ana Maria D’Avila; SANTOS JÚNIOR, Luís Haroldo Pereira dos. Minorias nacionais, proteção internacional e transnacionalidade. Revista de Direito Internacional. Brasília, v. 14, n. 3, p. 181-201, 2017.
No que se refere ao direito de acesso à informação ambiental, o Acordo delimita uma parte do público que, pelas próprias características, encontra dificuldades adicionais - às vezes intransponíveis - para exercer influência sobre decisões que irão determinar sua qualidade de vida ou de saúde. Seja porque a informação ambiental está disponível em diferentes bases de dados, é tecnicamente sofisticada ou exige a análise de um grande volume de dados, esse público é frequentemente excluído do debate ou sua participação é mediada, ocorrendo por meio de terceiros tecnicamente mais aptos. Todavia, o conhecimento e a experiência que esse público pode aportar ao debate tem o potencial de contribuir para melhores decisões para proteção ambiental e desenvolvimento sustentável, considerando a complexidade inerente ao processo, reduzida à medida que diferentes perspectivas sobre os problemas são efetivamente discutidas. Adotar instrumentos para facilitar a participação dos grupos vulneráveis das decisões em matéria ambiental aumenta as chances de alcançar boas decisões ${ }^{20}$.

Esse entendimento é particularmente relevante quando se discutem formas para viabilizar a efetiva participação de comunidades tradicionais na gestão de unidades de conservação, especialmente naquelas que não admitem sua presença. Considerada a vulnerabilidade especialmente característica desses grupos, que são deslocados para fora da unidade com o intuito de garantir sua própria diversidade, é rotineira sua exclusão do processo decisório relacionado à gestão da unidade, empobrecendo-o na medida em que nenhuma importância se confere a sua participação, a qual pressupõe o acesso a informações adequadas e tempestivas ${ }^{21}$.

Os principais instrumentos registrados no Acordo para viabilizar a participação de pessoas ou grupos em situação de vulnerabilidade nas decisões em matéria ambiental são a orientação e a assistência (artigo 4). Tais instrumentos se diferenciam, evidentemente: a orientação se refere à explicitação dos procedimentos para exercício do direito de acesso à informação ambiental,

20 POMADE, Adélie. El derecho a la información medioambiental: enfoque comparativo Francia-Brasil. In: GAUTREAU, Pierre; MONEBHURRUN, Nitisch (org.). Direito à informação ambiental: uma agenda de pesquisa interdisciplinar. Curitiba: Prismas, 2017. p. 93112.

21 LEUZINGER, Marcia Dieguez; SILVA, Solange Teles da. O princípio da participação e a criação e gestão das áreas protegidas na perspectiva do direito ambiental global. Revista de Direito Internacional, Brasília, v. 14, n. 3, p. 134-146, 2017. 
enquanto a assistência se materializa no processo de delimitação do pedido considerando-se a finalidade almejada pelo solicitante (artigo 5).

Essas disposições, certamente, foram inspiradas em relatórios e decisões do sistema interamericano de proteção dos direitos humanos, que teve a oportunidade de discutir o acesso à informação por grupos vulneráveis em, pelo menos, uma decisão exemplar, considerando a "interdependência" e a "sinergia entre direitos humanos e meio ambiente" 22 . Fazendo referência à decisão no caso Kichwa de Sarayaku versus Equador ${ }^{23}$, em 2012, ganha relevo o entendimento da Corte Interamericana sobre o caráter instrumental do direito de acesso à informação ambiental para garantia da consulta prévia, livre e informada dos povos indígenas e tribais, garantindo-se o direito à propriedade em consideração a sua identidade cultural e seu modo tradicional de vida. As decisões subsequentes, como o caso Claude Reyes versus Chile ${ }^{24}$, passaram a fundar o direito de acesso à informação na liberdade de pensamento e expressão, preceito geral de proteção do direito para todos, inclusive os grupos vulneráveis. A decisão no primeiro caso, todavia, destaca a especificidade das circunstâncias que justificam o acesso à informação ambiental por indígenas e grupos tribais, cuja consideração deve inspirar a assistência preconizada pelos dispositivos anteriormente transcritos.

A isenção dos custos para acesso à informação ambiental, para esse grupo, é justificável. Se é verdade que a LAI estabelece semelhante isenção, igualmente relevante é reforçá-la, considerando que o fornecimento da informação pode implicar gastos expressivos, especialmente para fotocópia e expedição de documentos (artigo 5).

Efetivamente transformadora será a determinação abaixo transcrita:

\begin{abstract}
6. A fim de facilitar que pessoas ou grupos em situação de vulnerabilidade tenham acesso à informação que os afete particularmente, cada Parte deverá fazer com que, conforme o caso, as autoridades competentes divulguem a informação
\end{abstract}

22 PERRUSO, Camila. Perspectivas do direito à informação ambiental no sistema interamericano de direitos humanos. In: GAUTREAU, Pierre; MONEBHURRUN, Nitisch (org.). Direito à informação ambiental: uma agenda de pesquisa interdisciplinar. Curitiba: Prismas, 2017. p. 293-312.

23 A decisão está disponível em http://www.corteidh.or.cr/docs/ casos/articulos/seriec_245_esp.pdf.

24 A decisão está disponível em http://www.corteidh.or.cr/docs/ casos/articulos/seriec_151_esp.pdf. ambiental nos diversos idiomas usados no país e elaborem formatos alternativos compreensíveis para esses grupos, por meio de canais de comunicação adequados (artigo 6 - grifo nosso).

A internet popularizou-se como meio de divulgação por excelência dos dados e informações detidos por órgãos e entidades públicos, não somente pelo baixo custo da disponibilização como pela alta acessibilidade, como regra. No entanto, a vulnerabilidade que caracteriza determinados grupos pode determinar o uso do rádio e do papel (entregue por barco), em diferentes línguas, para que a informação ambiental alcance, efetivamente, quem dela precisa. A disponibilização de dados e informações em formatos alternativos deverá envolver o uso de técnicas de design de informação, recorrendo-se a gráficos, tabelas, linhas do tempo, esquemas e imagens para rápida absorção de um conhecimento tão complexo como o embutido na informação ambiental, regra geral. Essas competências para síntese e comunicação de informação devem estar contempladas na constituição das equipes de funcionários e servidores públicos envolvidos em projetos de transparência de dados e informações ambientais, inclusive.

Para além dos artigos que tratam do acesso à informação ambiental por pessoas e grupos em situações vulneráveis, o Acordo de Escazú, também, dispõe sobre as condições para afastar negativas de acesso para proteção de interesses privados, em prol da ampliação da transparência e da participação social. A princípio, a possibilidade de alegação de um interesse público relevante deveria afastar a restrição de acesso a informações, aplicando-se essa "exceção da exceção". Assim, dispõe o Acordo:

9. Quando aplicar a prova de interesse público, a autoridade competente ponderará o interesse de reter a informação e o benefício público resultante de divulgá-la, com base em elementos de idoneidade, necessidade e proporcionalidade (artigo 5 - grifo nosso).

A LAI contém dispositivo semelhante, o qual permitiria afastar a proteção da privacidade em prol de um “interesse público geral e preponderante" (inciso $\mathrm{V}$ do parágrafo $3^{\circ}$ do artigo 31). Todavia, essa previsão genérica não traz quaisquer balizas para aplicação, de modo que os parâmetros indicados no Acordo poderiam lhe conferir densidade suficiente para aplicação, nos casos concretos. Nessa linha, o dispositivo presente na LAI determina que a proteção da privacidade deve ceder espaço, em situações excepcionais, aos benefícios coletivos da transparência ambiental. 
Aparentemente, o teste do interesse público, conforme proposto acima, se assemelharia a uma espécie de ponderação dos interesses em colisão (no caso da LAI, entre privacidade e acesso à informação, dois direitos fundamentais), exigindo-se avaliar os elementos designados como idoneidade, necessidade e proporcionalidade para se alcançar um resultado adequado. Essa ponderação assemelhar-se-ia, a princípio, com a Teoria Jurídica Geral dos Direitos Fundamentais conforme proposta por pelo jurista alemão Robert Alexy, a julgar pela redação final do teste do interesse público registrado no Acordo.

Com base em um conceito semântico de normas de direito fundamental, Alexy diferencia regras e princípios, propondo métodos para aplicação dessas normas. Considerando a existência de princípios como normas de direitos fundamentais, e que sua colisão se resolveria por meio do sopesamento de interesses, resultando em regras de precedência em condições determinadas, propõe a aplicação da máxima da proporcionalidade para fundamentação das regras de precedência. Adequação e necessidade, como elementos da máxima proporcionalidade, representariam critérios para se avaliarem as possibilidades fáticas para solução da colisão de princípios; o conceito de proporcionalidade, em sentido estrito, forneceria elementos para avaliação das possibilidades jurídicas ${ }^{25}$.

Carlos Bernal Pulido materializa essa regra em uma equação, propondo uma escala de 1 a 3 para avaliar o peso concreto de cada princípio em colisão, o peso abstrato e a confiança dos argumentos e dos pressupostos que conduziram à avaliação dos pesos concreto e abstrato dos princípios em colisão. Em complemento à proposta de Alexy, Bernal indica que a avaliação das certezas das premissas, no que se refere à fixação do peso concreto de cada princípios em colisão, considere a existência de premissas normativas (posição jurídica à luz do conceito de pessoa e conteúdo da posição jurídica da norma) e empíricas (eficiência, velocidade, probabilidade, alcance e duração da medida), as quais avaliam o efeito que a medida em discussão, no caso concreto, teriam sobre os princípios. Também adverte quanto à alta carga ideológica subjacente à avaliação do peso abstrato do princípio, a qual “(...) depende da pesquisa, pelo

25 ALEXY, Robert. Teoria dos direitos fundamentais. São Paulo: Malheiros, 2011. juiz, da melhor teoria substancial da constituição"26.

No entanto, o teste do interesse público, conforme descrito na parte inicial do dispositivo transcrito trata de raciocínio muito mais simples, qual seja, um "teste de balanceamento", avaliando-se se o interesse público em entregar a informação, no caso concreto, é maior do que o interesse privado de proteger a informação sigilosa. Esse balanceamento operaria por avaliação finalística, isto é, se a informação é fundamental para a finalidade da norma, qual seja, a transparência, o controle social e a participação social. Esse é o entendimento que se infere das leis de acesso à informação americana e irlandesa ${ }^{27}$, por exemplo, que associam o balanceamento à possibilidade de afastar a proteção de interesses privados (especialmente da privacidade) para permitir ao público conhecer a forma como atuam os órgãos e entidades governamentais, isto é, provendo a abertura do Estado $^{28}$. Na Irlanda, a decisão que determina o acesso à informação privada pode ser objeto de recurso administrativo pelo titular da informação, previsão que não encontra apoio explícito no Acordo de Escazú. Juan Carlos Upegui Mejía rechaça veementemente o recurso à ponderação, conforme aplicado no México pelo Instituto Nacional de Acesso à Informação (INAI), que estaria recorrendo à teoria de Alexy para legitimação política de decisões que melhor seriam adotadas se aplicado o balanceamento ${ }^{29}$.

Ao reunir, no mesmo dispositivo, dois diferentes métodos para solução de casos difíceis em matéria de proteção da privacidade e de acesso à informação ambiental (balanceamento de interesses versus ponderação de direitos fundamentais em colisão), o Acordo dificulta sua aplicação nos casos concretos, na contramão das conclusões recentes a partir da experiência regional ${ }^{30}$.

26 PULIDO, Carlos Bernal. La racionalidad de la ponderacion. In: CARBONELL, Miguel (ed.). El principio de proporcionalidade y la interpretación constitucional. Equador, 2008. p. 43-68.

27 Na página https://www.foia.gov é possível acessar a Lei de Liberdade de Informação americana e apresentar um pedido de acesso a informações. De igual modo, na página https://foi.gov.ie estão disponíveis informações e sistemas para acesso à informação na Irlanda.

28 LÓPEZ-AYLLÓN, Sergio; POSADAS, Alejandro. Las pruebas de daño e interés público en materia de acceso a la información: una perspectiva comparada. Derecho Comparado de la Información, Cidade do Mexico, n. 9, p. 21-65, 2007.

29 UPEGUI MEJÍA, Juan Carlos. Crítica a la ponderación como test de proporcionalidad para decidir sobre la publicidad de la información personal em poder del estado em Mexico. Derecho Comparado de la Información, Cidade do México, n. 10, p. 40-64, 2007

30 UPEGUI MEJÍA, Juan Carlos. Crítica a la ponderación como 
A LAI, entretanto, pode apontar solução conciliadora, viabilizando o acesso a informações pessoais quando demonstrado interesse público geral e preponderante, no caso concreto. Essa alegação é ônus do solicitante, mas, por inexistência de disposição em contrário, também poderia ser avaliada de ofício pelo órgão que recebeu o pedido, considerando o princípio da máxima divulgação.

De modo geral, ambos os conceitos (pessoas e grupos em situação de vulnerabilidade e teste do interesse público) deverão ser aplicados sob a perspectiva do Princípio da Máxima Divulgação e da principal finalidade do quadro normativo de acesso a informações ambientais, qual seja, o de garantir a transparência como opção regulatória para proteção do meio ambiente. $\mathrm{O}$ recurso à lei para exercer mera curiosidade sobre os assuntos privados de terceiros, ou que implique injustificável sobrecarga para os órgãos e entidades públicos, poderá ser considerado para negativa do acesso a informações de natureza ambiental, com as cautelas e critérios discutidos.

\section{Considerações finais}

O quadro jurídico brasileiro para acesso à informação ambiental é dotado de um conjunto de disposições que, alinhado com padrões internacionalmente aceitos, garante procedimentos, prazos e condições para o exercício adequado desse direito fundamental.

Com a entrada em vigor da LAI, em maio de 2012, a transparência ativa de dados e informações, em matéria ambiental, ganhou novo impulso, considerando as determinações para abertura de conjuntos de dados pelos três poderes e esferas de governo, tornando-os disponíveis para reuso. No entanto, não necessariamente o acesso se tornou mais simples e útil para aqueles que não estão familiarizados com softwares de tratamento de dados, podendo representar restrição da participação social àqueles que possuírem competências especializadas. Ao determinar que os Estados Parte adotem ações para viabilizar orientação e assistência a pessoas ou grupos em situação de vulnerabilidade, o Acordo de Escazú consolida precedentes do sistema interamericano

test de proporcionalidad para decidir sobre la publicidad de la información personal em poder del estado em Mexico. Derecho Comparado de la Información. Cidade do México, n. 10, p. 40-64, 2007. de proteção dos direitos humanos, especialmente dos povos indígenas e tribais, garantindo-lhes o direito à propriedade considerando sua identidade cultural e seu modo tradicional de vida. Para além da isenção de custos de reprodução de documentos, o Acordo determina, dentre outras obrigações, a disponibilização de dados e informações em formatos alternativos, demandando ações de design de informação, recorrendo-se a gráficos, tabelas, linhas do tempo, esquemas e imagens para rápida absorção de um conhecimento tão complexo como o embutido na informação ambiental, regra geral.

Para além das disposições que tratam do acesso à informação ambiental por pessoas e grupos em situações vulneráveis, o Acordo, também, trata das condições para afastar negativas de acesso à informação ambiental para proteção de interesses privados, em prol da ampliação da transparência e da participação social. A despeito de conter dispositivo semelhante ("interesse público geral e preponderante"), a LAI não traz quaisquer balizas para sua aplicação, de modo que os parâmetros indicados no Acordo poderiam lhe conferir densidade suficiente para aplicação, nos casos concretos. Todavia, o texto do Acordo parece dificultar a aplicação da regra, na medida em que reúne, no mesmo dispositivo, dois diferentes métodos para solução de casos difíceis em matéria de proteção da privacidade e de acesso a informação ambiental (balanceamento de interesses versus ponderação de direitos fundamentais em colisão). A LAI, portanto, constitui-se em fundamento para franquear o acesso à informação para a proteção ambiental que, também, se refira a pessoa natural identificada ou identificável, nos termos do inciso IV do artigo $4^{\circ}$. Desse modo, as inovações advindas do Acordo parcialmente incrementam a transparência ambiental em relação ao conjunto normativo atualmente em vigor.

Considerando-se a limitação de escopo da pesquisa, estudos comparados sobre avaliação de políticas públicas poderão contribuir para discussão interdisciplinar do tema. Do mesmo modo, pesquisas sob a perspectiva das relações de poder afetas ao direito fundamental de acesso à informação ambiental podem revelar conclusões interessantes para esse campo de pesquisa. 


\section{REFERÊNCIAS}

ALEXY, Robert. Teoria dos direitos fundamentais. São Paulo: Malheiros, 2011.

ALOGNA, Ivano; ALBUQUERQUE, Marcia Fajardo Cavalcanti de. Os modelos de divulgação de informação ambiental: experiências comparadas e perspectivas para o Brasil. In: GAUTREAU, Pierre; MONEBHURRUN, Nitisch (org.). Direito à informação ambiental: uma agenda de pesquisa interdisciplinar. Curitiba: Prismas, 2017.

BALBINO, Michelle Lucas Cardoso. A participação social na construção do direito ambiental global. Revista de Direito Internacional, Brasília, v. 14, n. 3, p. 79-104, 2017.

BANISAR, David. Freedom of information around the world 2006: a global survey of access to government information laws. Londres: Privacy International, 2006.

BARROS, Lucivaldo Vasconcelos. O Estado (in) transparente: limites do direito à informação socioambiental no Brasil. 2008. Tese (Doutorado em Desenvolvimento Sustentável) - Universidade de Brasília, Brasília, 2008.

PULIDO, Carlos Bernal. La racionalidad de la ponderacion. In: CARBONELL, Miguel (ed.). El principio de proporcionalidade y la interpretación constitucional. Equador, 2008.

CHOO, Chun Wei. A organização do conbecimento: como as organizações usam a informação para criar significado, construir conhecimento e tomar decisões. São Paulo: SENAC, 2003.

Comissão Interamericana de Direitos Humanos (CIDH). O direito de acesso à informação no Marco Jurídico Interamericano. 2011. Disponível em: https://www.oas.org/ pt/cidh/expressao/docs/publicaciones/20140519\%20 - $\% 20$ port $\% 20$ unesco $\% 20-\% 20$ el $\% 20$ derecho $\% 20$ de $\% 20$ acceso $\% 20 \mathrm{a} \% 201 \mathrm{a} \% 20$ informacion $\% 202 \mathrm{a} \% 20$ edicion\%20adjusted.pdf. Acesso em: 11 nov. 2018.

COSTA, Beatriz Souza; SAMPAIO, José Adércio Leite. Acesso à informação digital no Brasil em casos de acidentes: o exemplo da tragédia de Mariana. Revista $V_{e-}$ redas do Direito, Belo Horizonte, v. 14, n. 30, p. 77-98, 2017.

CUNHA FILHO, Marcio Camargo; XAVIER, Vitor Cesar Silva. Lei de acesso à informação: teoria e prática. Rio de Janeiro: Lumen Juris, 2014.

DIZ, Jamile Bergamaschine Mata; DISCACCIATI, Ana
Clara Gonçalves. Acesso à informação ambiental: por um novo paradigma de participação. Revista Direito e Liberdade, Natal, v. 17, n. 3, p. 71-113, 2015.

DONEDA, Danilo. Da privacidade à proteção de dados pessoais. Rio de Janeiro: Renovar, 2006.

GAUTREAU, Pierre. Entre democracia informacional y posneoliberalismo: una ecología política de los dispositivos de open data ambiental. In: GAUTREAU, Pierre; MONEBHURRUN, Nitisch (org.). Direito à informação ambiental: uma agenda de pesquisa interdisciplinar. Curitiba: Prismas, 2017.

LANCHOTTI, Andressa de Oliveira; DIZ, Jamile Bergamaschine Mata. Direito de acesso à informação ambiental: da formalidade à efetividade dos direitos de acesso. Revista de Direito e Sustentabilidade. Curitiba, v. 2, n. 2, p. 130-148, 2016.

LEUZINGER, Marcia Dieguez; SILVA, Solange Teles da. O princípio da participação e a criação e gestão das áreas protegidas na perspectiva do direito ambiental global. Revista de Direito Internacional, Brasília, v. 14, n. 3, p. 134-146, 2017.

LOPES, Ana Maria D’Avila; SANTOS JÚNIOR, Luís Haroldo Pereira dos. Minorias nacionais, proteção internacional e transnacionalidade. Revista de Direito Internacional. Brasília, v. 14, n. 3, p. 181-201, 2017.

LÓPEZ-AYLLÓN, Sergio; POSADAS, Alejandro. Las pruebas de daño e interés público

en materia de acceso a la información: una perspectiva comparada. Derecho Comparado de la Información, Cidade do Mexico, n. 9, p. 21-65, 2007.

MACHADO, Paulo Affonso Leme. Direito à informação e meio ambiente. 2. ed. São Paulo: Malheiros, 2018.

MENDEL, Toby. Liberdade de informação: um estudo de direito comparado. 2. ed. Brasília: UNESCO, 2009.

MICHENER, Gregory. Assessing freedom of information in Latin America a decade later: illuminating a transparency causal mechanism. Journal of Latin American Politics and Society, Miami, v. 57, n. 3, p. 11-99, 2015.

MONEBHURRUN, Nitisch. Estudo comparativo do Direito de acesso à informação ambiental na Argentina, no Brasil e na Bolívia: medindo os tons da transparência ambiental. In: GAUTREAU, Pierre; MONEBHURRUN, Nitisch (org.). Direito à informação ambiental: uma agenda de pesquisa interdisciplinar. Curitiba: Prismas, 
2017.

MORESO, José Juan. Alexy y la aritmética de la ponderación. In: CARBONELL, Miguel (ed.). El principio de proporcionalidade y la interpretación constitucional. Equador: Ministerio de Justicia y Derechos Humanos, 2008.

NAÇÕES UNIDAS. Declaração do Rio sobre meio ambiente e desenvolvimento. 1992. Disponível em: http://portal. iphan.gov.br/uploads/ckfinder/arquivos/Carta $\% 20$ do\%20Rio\%201992.pdf. Acesso em: 11 nov. 2018.

NAÇÕES UNIDAS. Declaración sobre los derechos de las personas pertenecientes a minorías nacionales o étnicas, religiosas y lingüísticas. 1992. Disponível em: http://www.ohchr. org/ Documents/Issues/Minorities/Booklet_Minorities_Spanish.pdf. Acesso em: 11 nov. 2018.

Organização para a Cooperação e Desenvolvimento Econômico (OCDE). Access to Public Information in Latin America. In: OPEN Government in Latin America. Paris: OCDE, 2014. Disponível em: http://www. keepeek.com/Digital-Asset-Management/oecd/governance/open-government-in-latin-america/access-topublic-information-in-latin-america_97892642236396-en\#page28. Acesso em: 11 nov. 2018.

PAES, Luciano Marcos. Participação popular e acesso à informação ambiental para preservação do meio ambiente ecologicamente equilibrado. Revista Brasileira de Políticas Públicas, Brasília, v.5, n. 2, p. 277-287, 2015.

PERRUSO, Camila. Perspectivas do direito à informação ambiental no sistema interamericano de direitos humanos. In: GAUTREAU, Pierre; MONEBHURRUN, Nitisch (org.). Direito à informação ambiental: uma agenda de pesquisa interdisciplinar. Curitiba: Prismas, 2017.

POMADE, Adélie. El derecho a la información medioambiental: enfoque comparativo Francia-Brasil. In: GAUTREAU, Pierre; MONEBHURRUN, Nitisch (org.). Direito à informação ambiental: uma agenda de pe- squisa interdisciplinar. Curitiba: Prismas, 2017.

POZEN, David E. Transparency's Ideological Drift. Yale Law Journal, set. 2018. Disponível em: https://papers.ssrn.com/sol3/papers.cfm?abstract_id $=3120807$. Acesso em: 11 nov. 2018.

SANDRA, Nicolle; MAYA, Leroy. Compartir y difundir datos públicos medioambientales: estrategias en la amazonia francesa y brasileña. In: GAUTREAU, Pierre; MONEBHURRUN, Nitisch (org.). Direito à informação ambiental: uma agenda de pesquisa interdisciplinar. Curitiba: Prismas, 2017.

SANTANA, Ana Cláudia Farranha; SUGUIURA, Carolina. Acesso à informação ambiental e considerações metodológicas sobre avaliação: é possível identificar como funcionam os sistemas de informação? In: GAUTREAU, Pierre; MONEBHURRUN, Nitisch (org.). Direito à informação ambiental: uma agenda de pesquisa interdisciplinar. Curitiba: Prismas, 2017.

SCHREIBER, Anderson. Direitos da personalidade. São Paulo: Atlas, 2014.

SILVA, Thiago Antunes da. Avaliação do acesso ao SINIMA - Sistema Nacional de Informação sobre o meio ambiente. Perspectivas em Ciência da Informação, Belo Horizonte, v. 12, n. 3, p. 41-53, 2007.

SOLOVE, Daniel J. Understanding Privacy. Cambridge: Harvard University Press, 2008.

UPEGUI MEJÍA, Juan Carlos. Crítica a la ponderación como test de proporcionalidad para decidir sobre la publicidad de la información personal em poder del estado em Mexico. Derecho Comparado de la Información, Cidade do México, n. 10, p. 40-64, 2007.

VLEUGELS, Roger. Overview of all FOI laws. Disponível em: http://www.right2info.org/resources/ publications/laws-1/ati-laws_fringe-special_rogervleugels_2011-oct. Acesso em: 11 nov. 2018. 
Para publicar na Revista de Direito Internacional, acesse o endereço eletrônico www.rdi.uniceub.br ou www.brazilianjournal.org.

Observe as normas de publicação, para facilitar e agilizar o trabalho de edição. 